\title{
Jack Antel: Canadian Leader in Neurology
}

\section{Adil Harroud}

Keywords: Education, Multiple sclerosis, Communication

doi:10.1017/cjn.2018.327

Can J Neurol Sci. 2018; 45: 696-697

The Canadian Leaders in Neurology series are an initiative of the Canadian Neurological Society whose objective is to showcase exceptional accomplishments by Canadian neurologists who are leaders in their respective fields. In this inaugural segment of the series, Adil Harroud, a neurology resident at McGill University, interviews Jack Antel, the first recipient of this distinction (Figures 1 and 2).

Antel is a clinical neurologist and neuroimmunologist based at the Montreal Neurological Institute (MNI). His major contributions to the field of multiple sclerosis (MS) were recognized by the 2005 Dystel Award from the National Multiple Sclerosis Society and the American Academy of Neurology. He is currently the president of the Americas Committee for Treatment and Research in Multiple Sclerosis (ACTRIMS).

Adil Harroud: Antel, you've had such a distinguished career as a clinician scientist. Surely, you must have careful planned every step of your career. Is that so?

Jack Antel: I don't think many of us planned our career. We followed the opportunities as they came up. We were fortunate to be asked to do things that were in our interest, and many of the options that came up were by chance. For example, when I was doing my fellowship in Boston, my mentor Barry Arnason was offered a position as Head of Neurology at the University of Chicago. I would never had considered the University of Chicago because I wasn't from there and didn't know very much about it, but ended up being on the faculty because of Barry's move. I ended up having a wonderful 10 years there. These options come up and, in many ways, one has to try to fit them in with their personal life.

\section{AH: How important is it to have mentors in one's career?}

JA: I think mentors are incredibly important. It starts from being fortunate to encounter someone who you just admire for what they do. When I started at McGill as an intern, there was a clinical immunologist named Phil Gold. I am not sure I entirely understood what research he was doing, but I knew this was adding a level of excitement. The first abstract I ever presented was at a Canadian meeting and was on a case report done with Phil. That turned out to be important because when I was a resident, my mentor in Neurology - the late Maurice Victorencouraged me to try to do something above the clinical practice, without ever downplaying its importance. He asked if I had ever seen something that was of interest and I mentioned immunology.
Then he arranged for me to work with Barry, and once I worked with him, I knew that's what I was going to do.

The other thing, in term of mentors, is at the level of someone creating the structure in which you work. Here, I would bring up the name of Don Baxter, the late director of the MNI. When he recruited me, he said: "You do what you want, and I'll take care of everything else". Even to this day, I am not sure what arrangement was made between the MNI and the MS Society of Canada to put in place the resources that allowed our team to move here from Chicago. I've been very fortunate to have Don to protect me early on and enable me to do what I wanted to do.

AH: The Quebec federation of specialists wrote an article in your honor which was titled "100 meters in 50 years". Can you explain to us the meaning of this title?

JA: When I was completing high school in Winnipeg, where I was born, my high school principal encouraged one or more of us to go away for university. He arranged for me to go to McGill, a place which was not known to me at the time. My father was a graduate of the University of Manitoba, and he thought that Manitoba was a perfectly good place to go to school. As it happened, I was sent to McGill and was arbitrarily assigned to a dormitory which turns out to be just above where the MNI is located. That's where I spent 3 years before going back to Manitoba for medical school. I've now been back at McGill for 30 years, and I was assigned to park in the small parking lot next to the exact residence where I lived as an undergraduate. In fact, if you ask how far is my car to my room as an undergrad, I could literally touch the room!

AH: As president of ACTRIMS, you were involved in the creation of the Neurology Resident Summit. Could you tell us more about this initiative?

JA: ACTRIMS was started about 15 years ago. We felt it should be a forum for North American based neurologists, while interacting with our European counterparts at the European Committee for Treatment and Research in Multiple Sclerosis (ECTRIMS). ECTRIMS evolved into a very large meeting and

From the Department of Neurology and Neurosurgery, McGill University, Montreal, Quebec, Canada.

Received July 5, 2018. Date of Acceptance July 16, 2018.

Correspondence to: A. Harroud, Montreal Neurological Institute and Hospital, 3801 University Street, Montreal, QC, Canada. Email: adil.harroud@mail.mcgill.ca 


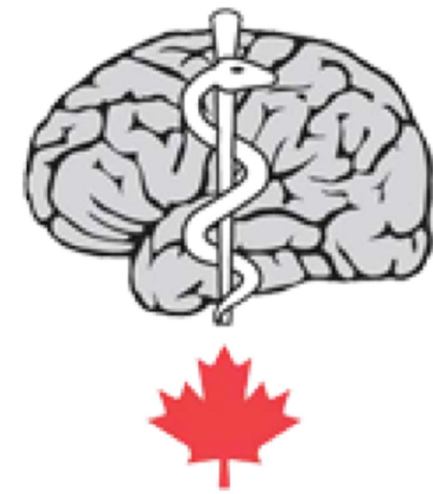

Figure 1: The Canadian Leaders in Neurology series are an initiative of the Canadian Neurological Society.

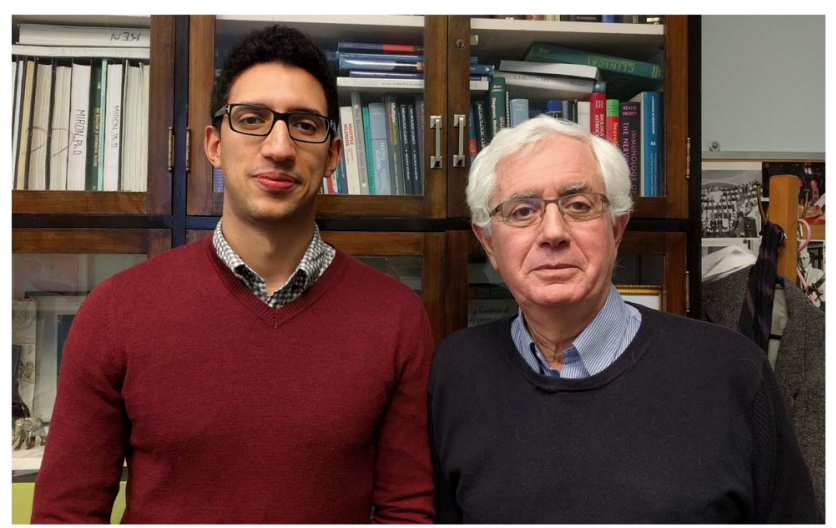

Figure 2: Jack Antel (left) in his office, with Adil Harroud (right), neurology resident, who conducted the interview.

still is the central clinical MS meeting. We felt that at ACTRIMS we should have an annual meeting where we could focus on a topic of specific interest in MS and also try to encourage new people to enter the field. As this has evolved over the last few years, we felt that almost the top importance was to encourage residents in neurology to consider careers that included or exclusively involved MS. We felt we could do this best by establishing a forum where residents would have a designated teaching program about MS itself and also find out what careers that involve MS could look like. We are fortunate that we have resources to bring the residents, so we don't have to be dependent on their programs. We would rather invest in a large number, fully understanding that only a minority may select MS. But I think that the knowledge they gain is worth for everybody even if they elect to do something else.

\section{AH: What are you most excited about in your field?}

JA: Difficult question to answer. An overall bridging answer is the opportunity to really do translational work. In other words, things being done in the laboratory can move to the clinics, and if you raise a question from the clinics there are ways to bring it back to the laboratory. The disease lends itself for study, which I think is very attractive. Many of us would feel now that understanding the progressive disability that occurs in MS is a major issue that we need to take on. I guess that attracts my attention because I think I have some of the tools with which to address that question. What we really want to do is prevent the disease, but that I am less sure that I have tools to contribute to that.

\section{AH: What advice would you give your 20-year-old self?}

JA: For me it's been very rewarding to have followed the path that I did, where I worked in sheltered environments both in Chicago and here, being able to use my clinical training and to interface it with laboratory training. Still the advice that I would give myself is that follow what you're interested in. If it interests you, go for it and don't be persuaded by someone who says, "but you could be doing something else". Most of us made short-term decisions. We did what we thought would be fun to do! Then you also need to have the good fortune on your side of being in the right place at the right time.

\section{AH: Is there someone within or outside medicine who inspires you?}

JA: Some people think of the big questions. I have a very close friend and colleague in Boston, Howard Weiner, who put out a wonderful movie called "What is life". I am more focused on what I'm doing. Sure, I am interested in the bigger questions, but I am not sure I am going to contribute to them.

\section{AH: What is your favorite leisure activity?}

JA: During the summer, I like to get outside. Put me on a golf course and give me a ball, and I'm a happy person. I'm not a big winter sports person, so if Montreal had the same climate as San Diego, I think I would do very well.

\section{AH: Antel, is there anything you wish to add?}

JA: I want to mention that a key thing for me was to be in an environment where I have colleagues and friends, to work in the academic environment and interact with people in my laboratory, and with residents who have shared interests with me. That's what created the enthusiasm and excitement. I think working in a vacuum would have been very difficult.

\section{ACKNOWLEDGEMENTS}

The author would like to thank Dr. Fiona Costello, president of the Canadian Neurological Society, for her major contribution to the design and realization of the Canadian Leaders in Neurology series.

\section{Disclosures}

The author has no conflicts of interest to declare. 